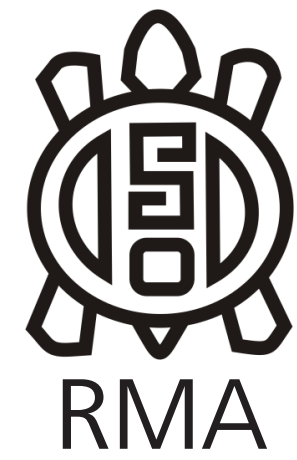

Arqueología

\title{
La alimentación prehispánica en las tierras bajas de Tucumán (Argentina): una primera aproximación a su análisis
}

\author{
Prehispanic food in the lowlands of Tucumán (Argentine): a first \\ approach to its analysis
}

\author{
Mario A. Caria*, Julián Gómez Augier**, Gabriel E. Miguez***
}

\begin{abstract}
*Facultad de Ciencias Naturales e IML. Universidad Nacional de Tucumán-CONICET.
E-mail: mcaria1@yahoo.com.ar

**INGEMA. Facultad de Ciencias Naturales e IML. Universidad Nacional de Tucumán.

E-mail: julianpgaugier@hotmail.com

***IAM. Facultad de Ciencias Naturales e IML. Universidad Nacional de Tucumán.

E-mail: gabrielmiguez7@hotmail.com
\end{abstract}

\begin{abstract}
Resumen
Este trabajo presenta una caracterización de los recursos alimenticios, al mismo tiempo que aborda la problemática de la alimentación prehispánica de las tierras bajas de la Provincia de Tucumán, Argentina. En base a los trabajos de diferentes investigadores en esta zona, se analizan las evidencias y contextos arqueológicos de hallazgos de alimentos, a la vez que se discuten algunos aspectos vinculados a los modos de obtención, producción y circulación de los mismos en el ámbito regional. Se observa que existió un aprovechamiento muy diverso de recursos, tanto silvestres como domesticados, durante el $1^{\circ}$ y $2^{\circ}$ milenio d.C. Esto permite distinguir, en una primera aproximación, entre aquellos alimentos obtenidos mediante caza, recolección y pesca, de aquellos producidos mediante el cultivo de plantas o la cría de animales. La preparación de comidas, en base a todos estos recursos, implica que los grupos del área debieron practicar mecanismos de control de los mismos mediante la horticultura, la caza y cría de animales, mayoritariamente locales, en complementación con los recursos obtenidos mediante redes de intercambio, reciprocidad y/o explotación directa de diferentes pisos ecológicos.
\end{abstract}

Palabras clave: Alimentación prehispánica; tierras bajas; $1^{\circ}$ y $2^{\circ}$ milenio d.C.; Tucumán; Argentina.

\begin{abstract}
This work presents a characterization of food resources and pre-Hispanic feeding in Tucumán Province lowlands, Argentina. Based on the work of different researchers in this area, the archaeological evidences and contexts of food findings are analyzed, while some aspects related to the ways of obtaining, producing and circulating them at a regional level are discussed. It is observed that there was a very diverse use of food resources, both wild and domesticated, during the 1st and 2nd millennium AD. This makes it possible to distinguish, at a first approach, between those obtained by hunting-gathering and fishing, from those produced by crop harvesting or raising animals. The preparation of meals, based on all these resources, implies that the groups in the area had to practice control mechanisms for them through horticulture practice, hunting and animal breeding, mostly local, in addition to resources obtained through exchange networks, reciprocity and/or direct exploitation of different ecological floors.
\end{abstract}

Keywords: Pre-Hispanic diet; lowlands; 1st and 2nd millennium AD; Tucuman; Argentine.

\section{Introducción}

El objetivo de este trabajo es presentar una caracterización de los recursos alimenticios y, sobre la base de la misma, abordar la problemática de la alimentación prehispánica del sector de las tierras bajas de la Provincia de Tucumán, Argentina. El mismo se fundamenta en el escaso conocimiento de este tema para el área y en la ausencia de información sistematizada. A pesar de que existen datos y trabajos que mencionan algunos de los alimentos consumidos por los grupos humanos en el pasado, no contamos con un trabajo que reúna esta información y establezca, a su vez, una relación con el desarrollo cultural del área y el resto del Noroeste argentino. 
En base a los trabajos que diferentes investigadores venimos realizando en esta zona, se analizan las evidencias y contextos arqueológicos de hallazgos de alimentos, a la vez que se discuten algunos aspectos vinculados a los modos de obtención, producción y circulación de los mismos en el ámbito regional. La dimensión del estudio de la alimentación como un producto social complejo excede los alcances planteados en este trabajo. Sin embargo, la sistematización y clasificación de la materialidad presente en los sitios arqueológicos analizados resulta indispensable para estudiar, a futuro, los procesos culinarios propios de esta porción del territorio tucumano y su relación con los procesos socioculturales prehispánicos del NOA.

\section{Marco conceptual}

La alimentación adquiere dimensiones diversas según el tiempo y el tipo de grupo social que se estudie. Desde un enfoque arqueológico la caracterización de la alimentación se complejiza, ya que debe recurrir a diversas materialidades y contextos -incompletos y alterados- para poder dimensionar los procesos y acciones subyacentes en el simple y vital acto de comer.

Históricamente, la alimentación ha sido considerada como un elemento intrínseco al desarrollo de los diferentes procesos sociales, entre los cuales se encuentran las diversas formas de relaciones entre los individuos y su entorno, las actividades ligadas a la producción de bienes, la cosmovisión y la jerarquización de los agentes humanos y no humanos dentro de un grupo social determinado (White et al. 2001). Las investigaciones que dan cuenta del estudio de la alimentación han debido distinguir una serie de conceptos para poder abordar con mayor precisión la subsistencia del hombre. Así, alimento, comida, dieta, nutrición y subsistencia, presentan distinciones propias (Ávido 2012) y pueden ser abordados desde diferentes líneas de investigación, según la pregunta que se pretenda responder. Por ello, la identificación de los diferentes recursos alimenticios, entendidos estos últimos como los elementos que están supeditados a su prevalencia en el medio ambiente y al intercambio entre grupos sociales (Cadena y Moreano 2012), posibilitan el abordaje para el estudio de los tipos de alimentos y las formas que adquiere la alimentación en nuestra área. En este sentido, los conceptos de alimento y alimentación, proporcionan el marco de referencia para la caracterización que es objeto de este trabajo, entendiendo a la alimentación como el "conjunto de acciones y relaciones sociales que se estructuran en torno al acto central de ingesta de sustancias alimenticias que pueden, o no, estar relacionado a la perpetuación del organismo vivo" (Marschoff 2007:156), y a los alimentos como todo aquello que puede ser ingerido por una persona (DaMatta 1987). Estos conceptos son los que mejor se ajustan a nuestro enfoque, ya que nos permiten, luego de una caracterización de los recursos alimenticios consumidos en los espacios prehispánicos de las tierras bajas tucumanas, proponer una serie de cuestiones vinculadas a los modos de vida de los grupos humanos que habitaron el área en relación directa o indirecta con éste y otros entornos. Por ello, en la caracterización y sistematización de las diferentes evidencias de recursos alimenticios recuperados del registro arqueológico, resulta importante distinguir entre aquellos alimentos consumidos en su forma natural, es decir sin una intervención que produzca una alteración física y/o química, de aquellos otros que han sido preparados de alguna manera antes de ser consumidos y, por ende, total o parcialmente modificados (Díaz 2009; Ávido 2012). Todos estos conceptos nos permiten, en este trabajo, realizar interpretaciones focalizadas en la subsistencia de los grupos prehispánicos de las tierras bajas. Cuando hablamos de subsistencia lo hacemos en los términos propuestos por Piperno y Pearsall (1998), quienes consideran a la misma como una serie de actividades tendientes a la preservación de los individuos, a la utilización de su entorno ecológico, a la gestión de los recursos y a la adaptación al ambiente. Sobre la base de este marco conceptual realizaremos una primera aproximación a la problemática de la alimentación prehispánica del área, la que consideramos, dada su centralidad y transversalidad a los demás aspectos de la vida de los grupos, relevante para un conocimiento más amplio y profundo de los mismos.

\section{Características generales del área y su arqueología}

\section{Área de Trabajo}

Las tierras bajas tucumanas pueden ser consideradas como una porción de la macro área pedemontana, que comprende el borde oriental andino desde el Noroeste argentino hasta el norte de Sudamérica.

Topográficamente, las tierras bajas tucumanas están representadas principalmente por el piedemonte, la llanura y la cuenca Tapia-Trancas. El piedemonte se desarrolla entre los 400 a 700 msnm, en la transición entre la llanura tucumana al oriente y las cadenas montañosas al oeste y se extiende desde las Sierras del Noreste hasta las Sierras del Sudoeste. Presenta un relieve de colinas con inclinación hacia el este y sudeste, por donde escurren los cauces fluviales actuales. La llanura se extiende desde los $400 \mathrm{msnm}$ hasta los $250 \mathrm{msnm}$ hasta el límite con Santiago del Estero. Esta unidad fisiográfica se desarrolla en todo el este de la provincia y se caracteriza por presentar una importante red hidrográfica. Con respecto a la cuenca Tapia-Trancas, se la considera una unidad propia de valles y cuencas intermontanos que se ubica en el centro-norte de la provincia con una altura de 600 a 700 msnm (Caria 2004). Todas estas unidades fisiográficas que conforman las tierras bajas presentan además complejos sistemas biológicos y sociales que le confieren características particulares en el ámbito de la provincia y la región (figura 1). 


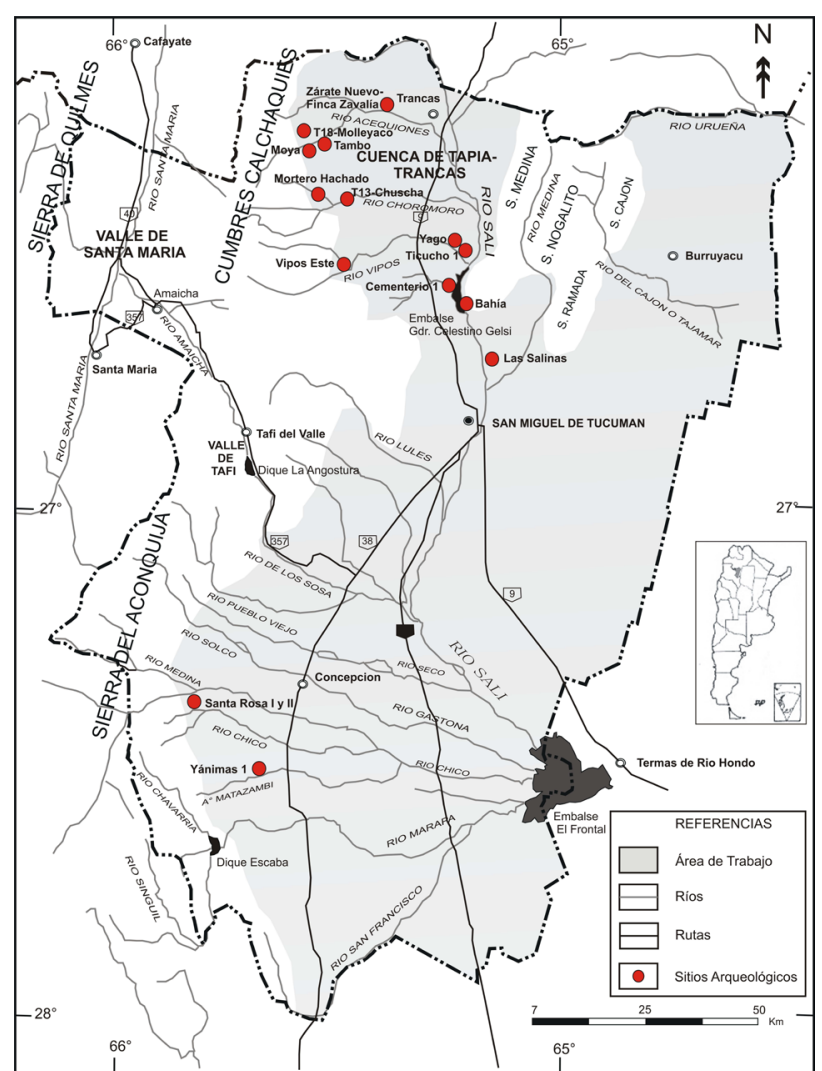

Figura 1. Sector de las tierras bajas en la provincia de Tucumán

Figure 1. Lowland sector in the province of Tucumán

Probablemente, el rasgo más sobresaliente de esta área lo constituya la presencia de una importante cubierta vegetal en forma de bosques que, con la excepción del lecho de ríos y depresiones con concentraciones salinas, ocupaban originalmente casi toda la superficie.

En términos generales, el gradiente de precipitación en el área se incrementa de este a oeste, hasta alcanzar sus valores máximos $(1800 \mathrm{~mm})$ sobre las laderas orientales de las Cumbres Calchaquíes a los 1500 msnm. Esta condición genera una cierta heterogeneidad ambiental que se refleja en las comunidades bióticas y su composición (Halloy 1985). Así, en cuanto a la flora, encontramos una vegetación cuyos elementos pertenecen a la ecoregión del Chaco Serrano, como en el sector de Trancas, y de las Yungas en el piedemonte oriental de Cumbres Calchaquíes, Sierra del Aconquija y occidente de la Sierra de Medina. Es importante señalar que las Yungas presentan, además, faciaciones altitudinales, constituidas -conforme ascendemos- por la Selva Pedemontana, Selva Montana, Bosque Montano y Pastizales de Neblina, y por ecotonos de ecoregiones colindantes de gran riqueza y biodiversidad. El Chaco Serrano se ubica por debajo de los 1800 msnm en un gradiente de precipitación que va de los 500 a los 900 mm, hacia el oeste se encuentra en contacto con las Yungas formando lo que algunos autores denominan Yungas de Transición (Verboorst 1969; Brown y Pacheco 2005) caracterizada por especies como el palo borracho o yuchán (Ceiba chodatii), espinillo (Acacia caven), aguaribay (Schinus areira), horco quebracho (Schinopsis haenkeana) y sombra de toro (Jodina rhombifolia). También se encuentran bosques xerófilos de quebracho blanco (Aspidosperma quebracho-blanco), yuchán (Ceiba speciosa), algarrobo blanco (Prosopis alba), tipa (Tipuana tipu), mistol (Zyziphus mistol), sombra de toro (Jodina rhombifolia), guayacán (Caesalpinia paraguariensis), chañar (Geoffroea decorticans) y varios géneros de cactáceas (Trichocereus, cardones [Cereus sp.], tunas [Opuntia sp.]). La ecoregión de las Yungas, según el gradiente altitudinal, incluye formaciones de selvas caducifolias, nuboselvas de montaña, bosques templados de altura y pastizales de alta montaña, donde pueden encontrarse más de 3000 especies de plantas vasculares, 57 familias, 130 géneros y 170 especies arbóreas (Cabrera 1976). El piso inferior, prácticamente desaparecido actualmente por la actividad antrópica está ocupado por la Selva Pedemontana (600 a 1500 msnm) y está caracterizado por especies como el Cebil (Anadenanthera macrocarpa y A. colubrina), la tipa (Tipuana tipu), el pacará (Enterolobium contortisiliqum), el tarco (Jacaranda mimosifolia) y el lapacho rosado (Tabebuia avellanedae). La Selva Basal (600 a 900 msnm) o selva de laurel tucumano (Cinnamomun porphyria) y tipa (Tipuana tipu) se asocia con intermedios de humedad entre la selva Pedemontana y el piso de vegetación formado por Mirtáceas y Tipa. Entre los 1000-1500 msnm, asociado con el óptimo pluvial, se encuentra la Selva de Mirtáceas. El Bosque Montano representa el límite altitudinal del bosque caracterizado por las neblinas. Las especies que la demarcan son el pino del cerro (Podocarpus parlatorei), Queñoa (Polylepis australis), alisos (Alnus acuminata), cedro del cerro (Cedrela lilloi), nogal criollo (Junglans australis) y palo yerba (Ilex argentinum) (Brown y Pacheco 2005).

Con respecto a la fauna, es importante conocer su composición por su vinculación directa con los sistemas de subsistencia de los grupos prehispánicos, es decir, los modos de apropiación de los mismos (caza de animales silvestres, cría o domesticación); las pautas de consumo (rangos etarios, estacionalidad) y la tecnología asociada. La confrontación de los registros actuales con la evidencia procedente del registro arqueológico permite, además, visualizar modificaciones en la estructura de las comunidades animales que pueden deberse a cambios ambientales o reflejar procesos de sobreexplotación antrópica (pasada o presente). No menos importante resulta la relación que en términos simbólicos se estableció entre el ser humano y la fauna cohabitante. La cosmovisión, expresada en la iconografía muestra este vínculo y pone de relieve la importancia atribuida a algunas especies como seres de ontologías equivalentes o nexos con el mundo de lo sobrenatural (Gómez Augier 2017; Moreno 2019).

Una rica variedad de animales habitan los diferentes ambientes de las tierras bajas de Tucumán. Entre los 
carnívoros encontramos representantes de las familias canidae, con cuatro especies de zorros (Cerdocyon thous; Pseudalopex culpaeus; $P$. griseus y $P$. gymnocercus). Entre los prociónidos encontramos al coatí o sacha mono y el osito lavador (Nasua nasua y Procyon cancrivorus, respectivamente); mientras que entre los mustélidos se cuentan al zorrino común (Conepatus chinga), el hurón mayor (Eira barbara) y el hurón menor (Galictis cuja). Los felinos registrados son el gato de pajonal (Felis colocolo), el puma (Felis concolor), el gato montés (Felis geoffroyi) y el yaguorundi o gato moro (Felis yagouroundi). Los artiodáctilos se encuentran representados únicamente por el pecarí de collar o chancho del monte (Tayasuu tajacu) y las corzuelas roja y parda (Mazama americana y $M$. gouazoubira) (Olrog 1995). Dentro del orden xenarthra, familia dasypodidae, se han registrado quirquincho chico (Chaetophractus vellersus), armadillo (Euphractus sexcintus) y quirquincho bola (Tolypeutes matacus); la familia myrmecophagidae está representada por el oso melero (Tamandúa tetradactyla). También encontramos marsupiales como la comadreja común (Didelphis albiventris). Entre los roedores existen representantes de las familias Cricetidae, Caviidae y Chinchillidae (Bárquez et al. 1991). Los reptiles más abundantes son la víboras como la coral (Micrurus pyrrhocryptus), yarará ñata (Bothrops ammodytoides), de la cruz (Bothrops alternatus) y cascabel (Crotalus durissus). También es común, principalmente en el sector más seco del área, la Iguana o caraguay (Salvator merianae antes Tupinambis teguixin) (Pérez Miranda 2006). Entre las aves se destacan el guaipo (Rhvnchotus rufescens), urracas (Cvanocorax chrysops), la pava del monte (Penelope obcura), grandes loros como el guacamayo verde (Ara militaris) o el loro alisero (Amazona tucumana) y variedad de picaflores y rapaces entre otras (Olrog 1995).

La información histórica refiere además, para el área, la presencia de especies actualmente extintas, muchas de ellas de importancia económica y simbólica para los pueblos prehispánicos como se infiere de las representaciones en la iconografía, la información etnohistórica, los mitos y leyendas del folklore local y en menor medida de evidencias arqueofaunísticas recientemente recuperadas. Entre estas especies encontramos el jaguar o yaguareté (Panthera onca), el tapir o anta (Tapirus terrestris) y la taruca (Hippocamelus antisensis) (Chevez 1994). Otras especies que habitaron el área, pero que aparentemente experimentaron una retracción natural, son el tucán grande (Rhampastos toco), el aguará guazú o lobo de crin (Chrysocyon brachyurus) y el oso de anteojos (Tremarctos ornatus) (Gómez Augier 2017).

\section{Arqueología de las tierras bajas}

Desde el punto de vista del desarrollo cultural, las tierras bajas tucumanas pueden ser consideradas como un espacio de convergencia entre elementos procedentes de la cuenca amazónica, el área andina y la región del
Gran Chaco. Producto de esta posición particular, el área presenta características propias, distintivas y únicas -ambientales y culturales-, que han sido determinantes en los procesos de conformación y desarrollo sociocultural prehispánico del Noroeste argentino.

Las investigaciones arqueológicas realizadas hasta la fecha en el área proporcionaron información sobre las características de los sitios y materiales prehispánicos, principalmente cerámicos, líticos y óseos, entre otros, permitiendo obtener una visión general de los procesos sociales de los últimos 3000 años (Berberián y Soria 1970; Heredia 1974; Berberián et al. 1977; Esparrica 1999; Caria 2004, 2007; Miguez 2010; Pantorrilla y Núñez Regueiro 2006; Caria et al. 2011; Caria y Gómez Augier 2015, 2019; Miguez y Caria 2015; Gómez Augier 2017; Moreno 2019).

En líneas generales podemos decir que, a excepción del sitio Acequia en la localidad de Ticucho (Caria 2004), no existen evidencias de ocupaciones para el período Arcaico en el área (ca. 9000-2500 años AP); por ello no es posible realizar una caracterización arqueológica de los grupos humanos para este momento. Las características del área, con abundantes recursos animales y vegetales, permiten suponer, sin embargo, la presencia de grupos cazadores-recolectores, tanto de filiación chaqueñaamazónica como andina, para este período de acuerdo a lo propuesto por Gómez Augier (2017).

Por otra parte, desde ca. 2500 años AP y hasta ca. 1100 años $A P$, las evidencias arqueológicas muestran que los grupos humanos asentados en el área se encuentran ocupando asentamientos pequeños de carácter semisedentario, preferentemente localizados sobre glacis y terrazas fluviales, con una economía de base cazadorarecolectora con práctica hortícola complementaria (Heredia 1974; Caria 2004). Así definidos, los patrones de ocupación del espacio para el área mantienen una regularidad notable a lo largo del tiempo (Caria 2007; Caria y Gómez Augier 2019), con excepción de sitios como Yago y Yánimas donde se visualizan formas arquitectónicas diferentes (montículos y rampas, por ejemplo) que podrían estar evidenciando, a priori, una mayor complejidad en términos sociopolíticos. También, durante este momento se visualiza, especialmente a través del registro cerámico, la influencia o interrelación en el área con grupos portadores de estilos Condorhuasi, Vaquerías y Aguada, entre otros, provenientes todos ellos de sectores externos a la misma (Caria et al. 2011; Caria y Gómez Augier 2015; Miguez y Caria 2015) en contraposición con el estilo Candelaria, el cual ha sido tradicionalmente asignado como característico en nuestra área de estudio (Heredia 1974). Si bien conocemos el patrón de asentamiento predominante visible a través de la arquitectura y la dispersión de elementos en el espacio, poco es lo que conocemos aún de la relación establecida con el entorno en términos productivos. 
Aún está en discusión, inclusive, si los sitios pueden ser considerados como verdaderas aldeas, al menos en el sentido tradicional del término (Gómez Augier 2017). García Azcarate y Korstanje (1995) consideran que en su mayoría los sitios de las tierras bajas tucumanas sugieren concentraciones pequeñas de población, no llegando a estructurar aldeas ni poblados mayores y en donde la organización social correspondería a la de pequeños grupos familiares dispersos.

Hacia ca. 1100 años AP, correspondiente a momentos del periodo Tardío, el registro arqueológico muestra la influencia de grupos provenientes del valle de Santa María. Estos grupos, de mayor complejidad socio-política, ocuparon especialmente el sector septentrional de las tierras bajas (cuenca de Tapia-Trancas), adaptando la configuración de sus asentamientos a las características particulares de este nuevo ambiente, aunque manteniendo en algunos casos las configuraciones propias de sus lugares de origen (Berberián y Soria 1970; Berberián et al. 1977; Esparrica 1999; Caria 2004). Es probable que la disminución en las precipitaciones, registradas a partir de los estudios paleoambientales en la región (Caria 2004; Gómez Augier y Caria 2012), favoreciera la migración de poblaciones localizadas en los valles de altura hacia las tierras bajas como una estrategia orientada a contrarrestar los efectos adversos, particularmente sobre la provisión de recursos vegetales en los núcleos residenciales de origen. A pesar de esta situación, es llamativo observar que el advenimiento de estas poblaciones no parece haber significado la alteración y ruptura de las formas de vida pre-existentes en los grupos de las tierras bajas; incluso es posible observar un uso común del espacio funerario (Caria 2007; Caria y Gómez Augier 2015; 2019). Muchos de estos cementerios muestran que los mismos se encontrarían operativos desde el período Formativo hasta el Tardío, mostrando algún tipo de vínculo o continuidad (histórica-cultural-biológica) y/o la coexistencia temporal entre las poblaciones consideradas como pertenecientes a tradiciones divergentes (andina/ amazónica).

\section{Contexto de hallazgo de recursos alimenticios en sitios del área de trabajo}

Del universo total de sitios conocidos hasta el momento (97), consideramos para nuestro análisis sólo aquellos sitios (14) cuyos contextos y materiales recuperados nos permiten inferir aspectos, directa o indirectamente, vinculados a la problemática de la alimentación prehispánica. Se detallan las características generales de los sitios y los hallazgos, cronología y análisis referidos a evidencias de alimentos en todas sus formas (alimentos sin preparación y alimentos preparados).

\section{Sitio Cementerio $N^{\circ} 1$ (Trancas)}

Este sitio está caracterizado por la presencia de 13 cistas con paredes de piedra en falsa bóveda y más de
50 urnas tipo santamariano tricolor y ordinario alisado por marleado con inhumaciones de párvulos. Berberián y Soria (1970:170) mencionan que "en algunos casos pudo observarse que encima de las lajas que cumplían la función de tapa de las cistas, se encontraban restos óseos correspondientes a auquénidos -muy posiblemente guanacos-, cáscaras de huevos de ñandú y numerosos fragmentos de alfarería (piezas rotas intencionalmente sobre la tumba?)". El sitio fue ubicado cronológicamente en el $2^{\circ}$ milenio d.C. en base a la presencia predominante de cerámica santamariana tricolor.

\section{Sitio Zarate Nuevo-Finca Zavalía (Trancas)}

En este sitio se localizaron estructuras de piedra circulares o sub circulares, sin un patrón definido y con una gran cantidad de artefactos de molienda (enteros y fracturados) a los que se le realizaron muestreos para análisis de fitolitos. También se registraron fragmentos grandes de cerámica de estilo Candelaria, presumiblemente pertenecientes a una urna utilizada para el enterramiento de párvulos; junto a estos fragmentos se registraron algunas rocas planas de filitas como las que usualmente se utilizan como tapas de enterratorios propias del primer milenio d.C. según Heredia (1974).

Se realizó el análisis de microfósiles en uno de los artefactos de molienda que arrojó la presencia de fitolitos con predominio de Poáceas afines a maíz, lo que induce a pensar que probablemente se efectuara en este artefacto molienda de granos de maíz (Gómez Augier 2017).

\section{Sitio Mortero Hachado (Trancas)}

Este sitio está ubicado en la localidad de Rearte y consiste en estructuras con cimientos de piedra de forma subrectangular y circular. Hacia el sur de estas unidades se encuentra una zona de enterratorios asignadas a la cultura Santamariana (Esparrica 1999). La excavación de una de las estructuras circulares permitió poner al descubierto tres posibles recintos divididos entre sí por un muro construido con una doble hilera de tapia. En la superficie de ocupación se halló una posible estructura de combustión, artefactos de molienda, material cerámico, líticos y restos óseos de fauna. Por la organización del espacio y las características de los objetos muebles recuperados se sugiere que en estos espacios se habrían llevado a cabo actividades domésticas, como la molienda y la cocción de los alimentos según Esparrica (1999). Nasif et al. (2007), sobre un total de 395 restos óseos faunísticos, identificaron camélidos; cérvidos grandes como la taruca (Hippocamelus antisensis); gato montés (Leopardus geoffroyi); roedores como ocultos (Ctenomydae) y cuises (Caviidae); quirquinchos (Dasypodidae) y gaviotas serranas (Familia Lariidae). Algunos de los huesos de camélidos presentaban signos de haber sido quemados a diferentes temperaturas. El sitio fue ubicado cronológicamente por datación relativa en el $2^{\circ}$ milenio d.C. (Esparrica 1999). 


\section{Sitio T-13-Chuscha (Trancas)}

Este sitio está compuesto por alineamientos de piedra y un basurero. En este último se recuperaron unos "pocos huesos de aves y auquénidos (Ilama o guanaco)" (Heredia 1974:90). La cronología del sitio asignada por Heredia es de 200-400 años d.C.

\section{Sitio T-18-Molleyaco (Trancas)}

Este está integrado por recintos de planta sub-circular y la presencia de un basurero en el que se recuperaron "una cantidad relativamente grande de huesos de camélidos" (Heredia 1974:100). La cronología del sitio asignada por Heredia es de 400-700 años d.C.

\section{Sitio Moya (Trancas)}

Este sitio está ubicado en la localidad de San Pedro de Colalao; en él se excavó una estructura circular de piedras $(2,30 \times 3 \mathrm{~m})$. En el mismo se recuperaron fragmentos de cerámica del tipo Candelaria Rojo Grabado, tres fragmentos de hueso correspondientes a una epífisis distal de fémur derecho de camélido adulto (Caria 2004).

\section{Sitio Tambo (Trancas)}

Este sitio está ubicado en la localidad de San Pedro de Colalao. No se identificaron rasgos arquitectónicos en superficie, pero si una gran cantidad de materiales líticos, cerámicos y óseos. En excavación se registraron materiales arqueológicos constituidos principalmente por huesos humanos y animales, artefactos líticos compuestos por puntas y lascas de obsidiana y cerámica de los estilos Vaquerías, Condorhuasi y Candelaria. También se registraron carbones y sedimento ceniciento. Se realizó un fechado radiocarbónico sobre un hueso humano que arrojó una edad de 1809+49 AP (AA99228). La descripción macroscópica de los restos óseos humanos arrojó un NMI de 1. Los restos arqueofaunísticos están constituidos por partes óseas de mandíbula, falanges, costillas y vertebras de camélidos. Algunos de estos restos se encontraban quemados (Caria y Gómez Augier 2015).

\section{Sitio Vipos Este (Trancas)}

El sitio se localiza en la localidad de Vipos. Se registraron materiales arqueológicos consistentes en lascas de cuarcita rosada, fragmentos de cerámica propios del $1^{\circ}$ milenio d.C. y numerosos artefactos de molienda fracturados (conanas y morteros). Sobre dos de estos artefactos se realizó un análisis de microfósiles en los que se identificaron fitolitos de Poáceas (Gómez Augier 2017).

\section{Sitio Yago (Trancas)}

Se localiza en la localidad de Ticucho y se caracteriza por estar constituido por 30 estructuras de piedra de diferentes tamaños y formas, distribuidas de tal manera que conforman una especie de herradura perimetral con una depresión central. Constituyendo parte del perímetro del sitio y distribuidos sobre su superficie fueron registrados ocho instrumentos de molienda (morteros y conanas) confeccionados sobre rocas metamórficas y areniscas (Caría et al. 2011). Se excavaron tres estructuras circulares en las que se recuperaron huesos de fauna, en algunos casos mesclados con espículas de carbones, fragmentos cerámicos del estilo Candelaria, restos de cenizas e instrumentos líticos. El material arqueofaunístico de una de las estructuras fue fechado, arrojando una edad radiocarbónica de 1359 \$57 años AP (Caria y Gómez Augier 2015).

De cada uno de los instrumentos de molienda relevados se realizaron análisis de microfósiles, indicando una tendencia en el predominio de fitolitos de la familia Poaceae (gramíneas), siendo más representativos Panicoide (¿maíz?) y Cloridoides, a lo cual se le suma un alto número de diatomeas entre las cuales se identificaron en orden de importancia Pinnularia, Hantzschia y Diploneis. Asimismo, se observan numerosos fitolitos de especies aún no determinadas que apuntan a una utilización de variados recursos vegetales alimenticios, probablemente silvestres como domesticados. El registro de placas perforadas sugiere además la presencia de dicotiledóneas de poroto (Phaseolus vulgaris) y zapallo (Cucurbita máxima). La importante concentración de diatomeas y micro carbones en uno de los artefactos sugiere alguna preparación con agua o ceniza, probablemente la molienda de un maíz ya tostado, aunque no debería descartarse su presencia debida a procesos postdepositacionales en la cavidad del artefacto (Caria et al. 2011; Gómez Augier 2017).

Con respecto al material arqueofaunístico, las excavaciones permitieron recuperar 122 especímenes. Un $15 \%$ de los fragmentos de huesos largos (diáfisis) presentan fracturas en espiral y curva de carácter intencional y marcas de cortes. Algunos fragmentos de huesos cortos y epífisis muestran marcas tipo muescas atribuibles a la acción de carnívoros oportunistas como zorros. La muestra presenta también algunos especímenes que evidencian alteración térmica por exposición directa al fuego. Anatómicamente, en líneas generales, se pudieron identificar fragmentos de huesos largos (diáfisis y epífisis) y cortos como falanges, vértebras y láminas de costillas, así como también algunas piezas dentarias, placas de caparazón y valvas de moluscos. Taxonómicamente la muestra se compone en un $87 \%$ de fragmentos pertenecientes a camélidos de individuos jóvenes, adultos y adultos mayores de acuerdo a los criterios de secuencia de fusión epifisial y de erupción y desgaste dentario. Es interesante mencionar el hallazgo de un fragmento de diáfisis de metapodio de camélido sin fusionar, atribuible a un individuo neonato. Se registraron, asimismo, algunos huesos de aves medianas y pequeñas, aún no identificadas, y la extremidad posterior de un ave grande que se atribuye a ñandú (Rhea americana). Asimismo, se identificaron huesos pertenecientes a ciervo de los pantanos (Blastocerus dichotomus), placas de dasipódidos (Chaetophractus villosus?), huesos largos 
y maxilares de roedores tipo Ctenomys y extremidades de anfibios (anuros). Por otra parte, se constató la formatización por corte intencional de un fragmento óseo de ave. La gran variedad de especies identificadas en el sitio, con claro predominio de camélidos de todos los rangos etarios, sugiere que en este sitio se podrían haber estado consumiendo algunos de estos animales. Aún no podemos precisar si todos ellos formaron parte del repertorio alimenticio, pero si podemos que sí lo integraban el $15 \%$ de los fragmentos de huesos con fracturas y marcas de cortes intencionales (Caria et al. 2011; Gómez Augier 2017).

\section{Sitio Ticucho 1 (Trancas)}

Este sitio ubicado en la localidad de Ticucho está conformado por dos estructuras circulares e hileras rectas de piedras junto a artefactos de molienda. Se excavó una de las estructuras circulares (E1) recuperándose fragmentos cerámicos del tipo ordinario, huesos de animales identificados como de camélidos en mal estado de conservación y un fragmento de punta de proyectil de obsidiana. Se realizó un fechado por AMS sobre sedimento del piso de ocupación que dio una edad no calibrada de 1020 35 AP (NSRL-12171) (Caria 2004).

En la E1 se realizó un análisis polínico de los sedimentos, los cuales determinaron que las formas de vida o taxones estuvieron representados por una gran variedad de plantas. Para el presente trabajo sólo se mencionan aquellos con un posible uso comestible y para la combustión como Celtis sp., Prosopis sp., Schinus sp., Acacia sp., Larrea sp., Adesmia sp., Poaceae y Amaranthaceae-Chenopodiaceae (Caria 2004; Caria y Garralla 2006; Caria y Sayago 2008).

En dos artefactos de molienda (morteros) se identificaron, mediante análisis de microfósiles, oxalatos de calcio romboidales afines a Cebil (Anandenanthera colubrina),

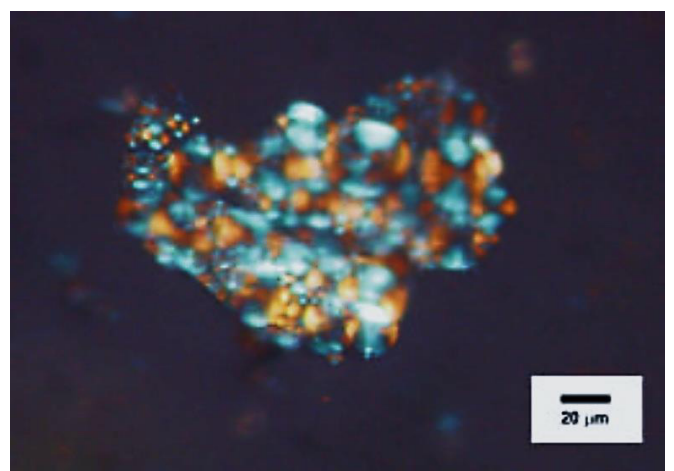

Figura 2. Conglomerados de almidones afines a Maíz (Zea mays) recuperados de morteros del sitio Ticucho 1 (tomado de Gómez Augier 2017)

Figure 2. Conglomerates of starches related to Maize (Zea mays) recovered from mortars from the Ticucho 1 site (taken from Gómez Augier 2017)

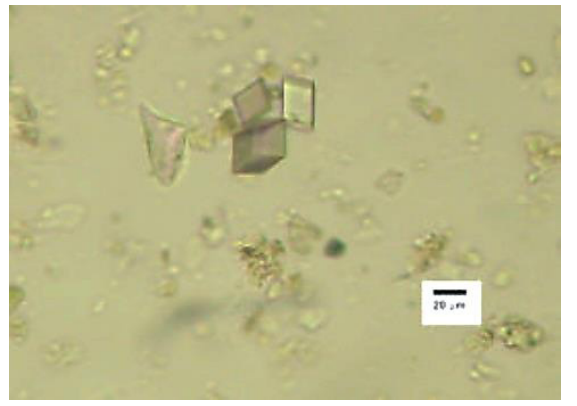

Figura 3. Oxalatos de calcio en forma de prisma y romboidales afines a Cebil y Mistol recuperados de morteros del sitio Ticucho 1 (tomado de Gómez Augier 2017).

Figure 3. Prism-shaped and rhomboidal calcium oxalates related to Cebil and Mistol recovered from mortars from the Ticucho 1 site (taken from Gómez Augier 2017)

fitolitos de Mistol (Ziziphus mistol), almidones afines a Maíz (Zea mays) y polen afín a cheno-amarantáceas y Poáceas (Figura 2 y 3). Estos microfósiles estarían indicando que los morteros tuvieron un uso múltiplo, tanto para la molienda de plantas comestibles cultivadas como silvestres y, al mismo tiempo, para la molienda de sustancias psicoactivas como el Cebil (Gómez Augier 2017).

\section{Sitio Bahía (Tafí Viejo)}

Se ubica en la localidad de El Cadillal, donde sobresale un alineamiento compuesto por cinco piedras canteadas, las que se excavaron recuperándose fragmentos cerámicos del estilo Vaquerías y Condorhuasi. También en la superficie del sitio se recuperaron 62 fragmentos de cerámica decorada de estilo Condorhuasi y Candelaria, lascas y puntas de obsidiana, junto a fragmentos óseos de mamíferos correspondientes a camélidos. También se recuperó un molar humano con presencia de hipoplasia simple, lo que indicaría probables problemas de nutrición en los primeros años de vida del individuo. Por los estilos cerámicos presentes se puede asociar al sitio a momentos tempranos del $1^{\circ}$ milenio d.C. (Caria y Gómez Augier 2015).

\section{Sitio La Salina (Burruyacu)}

Este sitio se encuentra ubicado en la localidad de El Timbó, sobre un acuífero de salmuera saturada de origen lacustre donde las placas de sal gema que lo contienen son disueltas por corrientes subterráneas de agua. Gómez Augier et al. (2007) registraron estilos cerámicos que se adscriben a sociedades valliserranas (Tafí, Condorhuasi, Aguada) y a entidades propias del piedemonte y llanura adyacente (Candelaria, Sunchituyoj y Averías) prolongando la secuencia de ocupación del sitio hasta momentos de contacto Hispano-indígena. Gómez Augier (2017) fechó restos de una diáfisis de camélido que arrojó una edad

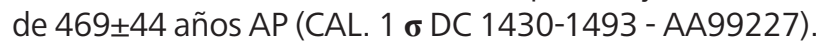
Estos autores consideran a la salina de El Timbó como un yacimiento significativo para la comprensión de 
la problemática cultural que presenta el piedemonte tucumano, ya que el mismo se erige como un importante espacio de convergencia multicultural para la explotación de la sal, quizás ya desde los comienzos del $1^{\circ}$ milenio d.C. hasta el período de contacto Hispano-indígena. Los grupos sociales procedentes de los valles y quebradas de altura estarían aprovechando este recurso en una zona ecológica distinta a la de sus asentamientos nucleares, a través de la instalación de colonias que responderían a un sistema similar al del control vertical, característico de ciertos sectores de los Andes centro-sur (Murra 1975). En cambio, para las entidades de las tierras bajas, ante todo, este acuífero debió representar la oportunidad de explotar la sal para consumo o para intercambiarlo por otros productos con grupos valliserranos o chaqueños. Los datos empíricos permitirían afirmar, además, que la técnica extractiva de sal fue la que utiliza la exposición de la salmuera al sol contenida en vasijas de factura tosca, las cuales en ocasiones pudieron haber sido expuestas directamente al fuego.

\section{Sitios Santa Rosa I y II (SRI y SRII) (Chicligasta)}

Estos sitios (SRI y SRII) se emplazan al pie de la ladera oriental de la Sierra del Aconquija. En SRI se relevaron molinos y morteros sobre grandes bloques de roca y artefactos de molienda móviles y fragmentos cerámicos. Se realizó una excavación junto a uno de los morteros fijos donde se registraron fragmentos de cerámica tosca, material lítico tallado y una mano de moler. El registro arqueológico indica que en este lugar se desenvolvieron acciones vinculadas al procesamiento de alimentos $u$ otras sustancias y también prácticas relacionadas con la selección de materias primas y talla de artefactos líticos (Miguez 2010).

En SRII, la excavación se efectuó junto a un alineamiento de piedras semi-circular con molino de mano asociado. Se registraron fragmentos cerámicos con residuos de carbón, en algunos casos asociados a carporestos termoalterados junto a un área rubefactada con carbones. Los carporestos carbonizados son escasos y se encuentran muy bien preservados. A partir de un análisis macroscópico y microscópico de caracteres cuantitativos (dimensiones) y cualitativos (forma, textura, superficie), estos restos se identificaron taxonómicamente como semillas de Phaseolus vulgaris var. vulgaris, que es la variedad domesticada del poroto común. Estas evidencias (restos y asociaciones) Ilevaron a proponer la existencia de un nivel de ocupación prehispánica, para el cual se obtuvo un fechado radiocarbónico de $1686 \pm 38$ años A.P. (AA94212, semilla) (Miguez et al. 2012).

En base a estos datos, Miguez et al. (2012) han planteado que en este lugar se efectuaban tareas como la preparación y consumo de alimentos a partir del uso de artefactos de molienda y vasijas expuestas al fuego, así como también acciones relacionadas con la talla y posible uso de artefactos líticos confeccionados en materias primas locales y también foráneas, entre otras actividades. Estos datos, sumado a los indicios de actividades culinarias, más el derrumbe y el posible fogón registrados, permiten pensar en un lugar residencial.

\section{Sitio Yánimas 1 (La Cocha)}

Este sitio se ubica en la ribera meridional del tramo superior del río Marapa y está conformado por un montículo y varias unidades arqueológicas entre las que se destaca un sector central (SC) (Miguez 2010). En los alrededores del SC el sitio presenta una gran cantidad de restos arqueológicos, representados por fragmentos cerámicos, artefactos de molienda, materiales líticos, entre otros. Miguez et al. (2012) excavaron parte del SC registrando fragmentos de vasijas, vestigios faunísticos y macrorestos vegetales carbonizados, cuatro tubos de pipas, un diente humano, tres cuentas de collar, dos laminillas de oro y un bezoar. Se identificó una asociación de fragmentos cerámicos grandes, cáscaras de huevo de Rhea americana, una extremidad articulada de Hippocamelus antisensis (taruca), caparazones de moluscos, restos de camélidos y otros animales y un silbato de hueso. Estos materiales y asociaciones se encontraban depositados en una matriz con abundantes carbones y manchas blanquecinas de aspecto ceniciento. De acuerdo con los fechados radiocarbónicos de 960 \pm 70 años A.P. (LATYR-2185, hueso) y 1060 \pm 60 años A.P. (LATYR-2403, hueso), el sitio de Yánimas habría sido ocupado entre ca. 1100800 años A.P. Miguez (2010).

Nasif y Miguez (2014) identificaron para este sitio, sobre la base de restos arqueofaunísticos, una alta diversidad de animales correspondiente a mamíferos, aves, reptiles, anfibios, peces y moluscos terrestres. Su identificación arrojó los siguientes resultados: 1) la clase mayoritaria es la de mamíferos $(91,36 \%)$, entre los cuales los Artiodactyla son el orden mejor representado $(61,92 \%)$, incluyendo cérvidos (Cervidae) y camélidos, así como restos no identificables asignados a artiodáctilos grandes y chicos; 2) los Rodentia (12,16\%) constituyen el segundo escalón en importancia cuantitativa e incluyen chinchillones y vizcachas (Chinchillidae), coipo (Myocastoridae), ocultos (Ctenomyidae), cuises (Caviidae), pericotes (Cricetidae) y roedores de diferente porte cuyos restos son no identificables a un menor nivel sistemático; 3) luego le siguen los Xenarthra (4,16\%), representados por quirquinchos (Dasypodidae) y 4) los Carnivora (Felidae) $(0,16 \%)$. También se contabilizan restos mal preservados que sólo pueden atribuirse a mamíferos medianos y chicos $(12,96 \%)$. En cuanto a los restos óseos de aves, si bien su proporción en la muestra es escasa $(0,96 \%)$, se reconocen varios taxa tales como Rheiformes, Accipitriformes, Passeriformes y aves medianas no identificadas. Cabe aclarar que también se han identificado gran cantidad de fragmentos de cáscaras de huevos correspondientes a Rhea americana, que no fueron contabilizados. Entre los restos de reptiles $(3,52 \%)$ se determinaron ejemplares 
del Orden Squamata (ofidios y lagartos chicos y grandes), mientras que los anfibios (2,08\%) están representados por los Anura de tamaño chico y grande. Por último, se registran restos de peces $(2,08 \%)$ correspondientes a los órdenes Siluriformes y Characiformes.

Este abanico de restos faunísticos refleja en su composición un amplio territorio, que abarca diferentes ambientes (pastizales de altura, selvas y chaco semiárido), altitudes (desde los 3000 a los 300 msnm) y hábitats (terrestres, aéreos y acuáticos). En algunos componentes de esta muestra, Nasif y Miguez (2014) identificaron fracturas intencionales y marcas de corte, principalmente en huesos de camélidos, quirquinchos y roedores. Probablemente estas huellas estén indicando que los mismos fueron consumidos y quemados en momentos previos a su depositación final en el sitio. En este conjunto arqueofaunístico predominan, claramente, los restos de camélidos (48\%) y cérvidos (8\%) por sobre el resto de las especies y/o taxones. Se destaca en el conjunto la presencia de Hippocamelus antisensis (taruca) (5,92\%), un ciervo considerado sagrado en la cosmovisión andina que es utilizado en rituales curativos (Califano 1976; Capriles Flores 2002; Arenas 2003).

Por otra parte, entre los macrorestos vegetales se registraron carporestos, mayormente carbonizados, de plantas silvestres como algarrobo (Prosopis nigra, Prosopis sp.), chañar (Geoffroea decorticans) y tala (Celtis sp.), así como también de especies domesticadas (Phaseolus vulgaris var. vulgar, Zea mays y Z. mays var. Oryzaea) (Miguez et al. 2012).

Los resultados obtenidos para este sitio permiten reconocer una gran diversidad de recursos animales y florísticos aprovechados (silvestres y domesticados), que muestran un amplio patrón de distribución biogeográfica. Así mismo, su análisis contextual sugiere que parte de estos recursos tuvo una activa participación en prácticas rituales y ceremoniales, ya sea como parte de ofrendas, comidas o como objetos con poderes especiales (Nasif y Miguez 2014).

\section{Los recursos alimenticios en los contextos arqueológicos analizados}

Del análisis de los materiales identificados para cada uno de los sitios antes mencionados puede observarse que existió un aprovechamiento muy diverso de recursos, tanto silvestres como domesticados, en el área de estudio. La variabilidad de tipos de plantas y animales registrados nos permite distinguir, en una primera aproximación, entre aquellos alimentos producto de la recolección, la caza y la pesca, de aquellos obtenidos mediante el cultivo de plantas o la cría de animales; en la Tabla 1 se sintetizan las evidencias tal como aparecen mencionadas en la bibliografía consultada para cada sitio. Cabe aclarar que, dada la disparidad en cómo se presentan los datos sobre los camélidos para los diferentes sitios, en especial aquellos trabajados por otros autores, optamos por no hacer la distinción entre especies domesticadas y silvestres. Esta decisión se basa, además, en que en el estado actual de las investigaciones para el área, no ha sido posible aún determinar con exactitud las especies de camélidos presentes en los diferentes sitios. Un estudio sobre esta temática en particular está siendo desarrollada por los autores en colaboración con especialistas en el tema. Por lo expuesto, el criterio utilizado para nuestro análisis es directamente el de Camélidos.

Del análisis realizado, podemos distinguir que: a) 97 sitios arqueológicos han sido registrados hasta el momento para el sector de las tierras bajas de Tucumán; b) sólo 14 sitios presentan evidencia directa de consumo o utilización de algún tipo de alimento; c) de estos 14 sitios, 9 corresponden a momentos del $1^{\circ}$ milenio $d$. C., mientras que 5 pueden ser asociados tanto al $1^{\circ}$ como al $2^{\circ}$ milenio d.C.; d) en 6 sitios se han registrado evidencias de algún tipo de planta comestible, en tanto 11 sitios presentan registro de animales comestibles; e) entre los sitios con evidencias de plantas, 3 registran plantas silvestres y 6 plantas cultivadas y g) sólo uno registra evidencia de otro tipo de alimento o complemento de la alimentación como ser la sal.

Con respecto a las plantas que se estaban consumiendo en todos estos sitios se pueden distinguir el maíz, el poroto y el zapallo, como plantas cultivadas; mientras que el algarrobo, el molle, el chañar, el cebil, el mistol, el tala y la jarilla están presentes como plantas silvestres. Por otra parte, el ñandú, el ciervo de los pantanos, la taruca, el quirquincho, las gaviotas serranas, los roedores y los peces están presentes como animales silvestres, siendo los camélidos los únicos animales que aún no podemos especificar si corresponden a las especies domesticadas o silvestres. En el caso particular de los roedores, no queda claro si los mismos se encuentran formando parte del registro arqueológico por acción directa del hombre o si son el producto de procesos tafonómicos naturales; de igual manera cabe dicha observación para las gaviotas serranas.

En cuanto al contexto de hallazgo de los recursos alimenticios, éstos se presentan en contextos domésticos y funerarios/ceremoniales. Las evidencias alimenticias provienen de 12 contextos considerados como domésticos; mientras que 4 fueron obtenidos tanto de contextos identificados como funerarios/ceremoniales y domésticos (es decir compartiendo el mismo espacio) y sólo uno corresponde a una cantera para la extracción de sal.

Sobre la base de estos resultados podemos observar entonces que de los 12 tipos de plantas comestibles registradas, sólo 4 de ellas (maíz, poroto, algarrobo y chañar) se encuentran presentes tanto durante el $1^{\circ}$ 
M. A. Caria et al. | Revista del Museo de Antropología 13 (3): 105-122 | 2020

DOI: http://doi.org/10.31048/1852.4826.v13.n3.28358

Tabla 1. Recursos alimenticios identificados en los sitios analizados

Table 1. Food resources identified in the analyzed sites

\begin{tabular}{|c|c|c|c|c|c|}
\hline Sitio & Periodo & Plantas comestibles & $\begin{array}{c}\text { Animales } \\
\text { comestibles }\end{array}$ & Otros & $\begin{array}{l}\text { Referencias } \\
\text { Bibliográfica }\end{array}$ \\
\hline Sitio Cementerio N¹ & $2^{\circ}$ milenio d.C. & - & $\begin{array}{l}\text { Ñandú (cáscaras de } \\
\text { huevo). Camélidos. }\end{array}$ & - & Berberián y Soria (1970) \\
\hline Zárate Nuevo-Finca Zavalía & $1^{\circ}$ milenio d.C. & Poáceas afines a maíz & - & - & Gómez Augier (2017) \\
\hline Mortero Hachado & $2^{\circ}$ milenio d.C. & - & $\begin{array}{c}\text { Taruca } \\
\text { (Hippocamelus } \\
\text { antisensis). } \\
\text { Gato montés } \\
\text { (Leopardus geoffroyi). } \\
\text { Roedores } \\
\text { (Ctenomydae y } \\
\text { Caviidae). } \\
\text { Quirquinchos } \\
\text { (Dasypodidae). } \\
\text { Gaviotas serranas } \\
\text { (Lariidae). Camélidos. }\end{array}$ & - & $\begin{array}{c}\text { Esparrica (1999); Nasif } \\
\text { et al. (2007) }\end{array}$ \\
\hline T-13-Chuscha & $1^{\circ}$ milenio d.C. & - & Aves. Camélidos. & - & Heredia (1974) \\
\hline T-18-Molleyaco & $1^{\circ}$ milenio d.C. & - & Camélidos & - & Heredia (1974) \\
\hline Moya & $1^{\circ}$ milenio d.C. & - & Camélidos & - & Caria (2004) \\
\hline Tambo & $1^{\circ}$ milenio d. $C$ & - & Camélidos & - & $\begin{array}{c}\text { Caria y Gómez Augier } \\
(2015)\end{array}$ \\
\hline Vipos Este & $1^{\circ}$ milenio d.C. & $\begin{array}{l}\text { Rafidios de tubérculos. } \\
\text { Fitolitos de Poáceas }\end{array}$ & - & - & Gómez Augier (2017) \\
\hline Yago & $1^{\circ}$ milenio d.C. & $\begin{array}{c}\text { Maíz (Zea mays). } \\
\text { Poroto (Phaseolusvulgaris). } \\
\text { Zapallo (Cucurbita máxima). }\end{array}$ & $\begin{array}{c}\text { Moluscos. } \\
\text { Aves. } \\
\text { Ñandú (Rhea } \\
\text { americana). } \\
\text { Ciervo de los } \\
\text { pantanos (Blastocerus } \\
\text { dichotomus). } \\
\text { Dasipódidos } \\
\text { (Chaetophractus } \\
\text { villosus). } \\
\text { Roedores (Ctenomys). } \\
\text { Anuros. } \\
\text { Camélidos. }\end{array}$ & - & $\begin{array}{l}\text { Caria et al. (2011); } \\
\text { Caria y Gómez Augier } \\
\text { (2015); Gómez Augier } \\
\text { (2017) }\end{array}$ \\
\hline Ticucho 1 & $2^{\circ}$ milenio d.C. & $\begin{array}{c}\text { Algarrobo (Prosopis sp.). } \\
\text { Molle (Schinus sp.). } \\
\text { Acacia sp. } \\
\text { Celtis sp. } \\
\text { Cebil } \\
\text { (Anandenantheracolubrina). } \\
\text { Mistol (Ziziphus mistol). } \\
\text { Jarilla (Larrea sp.). } \\
\text { Leña amarilla (Adesmia sp.). } \\
\text { Maíz (Zea mays). } \\
\text { Poáceas. } \\
\text { Cheno-amarantáceas. }\end{array}$ & Camélidos. & - & $\begin{array}{l}\text { Caria (2004); Caria y } \\
\text { Garralla (2006); Caria y } \\
\text { Sayago (2008); Gómez } \\
\text { Augier (2017) }\end{array}$ \\
\hline Bahía & $1^{\circ}$ milenio d.C. & - & Camélidos & - & $\begin{array}{c}\text { Caria y Gómez Augier } \\
(2015)\end{array}$ \\
\hline La Salina & $\begin{array}{c}1^{\circ} \text { y } 2^{\circ} \text { milenio } \\
\text { d.C. }\end{array}$ & - & Camélidos & Sal & $\begin{array}{c}\text { Gómez Augier et al. } \\
\text { (2007); Gómez Augier } \\
\text { (2017) }\end{array}$ \\
\hline Santa Rosa I y II & $1^{\circ}$ milenio d.C. & $\begin{array}{l}\text { Poroto común (Phaseolus } \\
\text { vulgaris var. Vulgaris). }\end{array}$ & - & - & $\begin{array}{c}\text { Miguez (2010); Miguez } \\
\text { et al. (2012) }\end{array}$ \\
\hline Yánimas 1 & $\begin{array}{c}1^{\circ} \text { y } 2^{\circ} \text { milenio } \\
\text { d.C. }\end{array}$ & $\begin{array}{c}\text { Poroto común (Phaseolus } \\
\text { vulgaris var. Vulgaris). } \\
\text { Maíz (Zea mays y Z. mays var. } \\
\text { Oryzaea). }\end{array}$ & $\begin{array}{c}\text { Rhea americana. } \\
\text { Taruca } \\
\text { (Hippocamelus } \\
\text { antisensis). Moluscos } \\
\text { gasterópodos. } \\
\text { Roedores } \\
\text { (Ctenomydae y } \\
\text { Caviidae). } \\
\text { Quirquinchos } \\
\text { (Dasypodidae). } \\
\text { Reptiles. Anuros. } \\
\text { Bagres (Pimelodus } \\
\text { labrosus). } \\
\text { Bogas (Leporinus } \\
\text { fasciatus). Camélidos. }\end{array}$ & - & $\begin{array}{c}\text { Miguez (2010); Nasif y } \\
\text { Miguez (2014); Miguez } \\
\text { y Caria (2015) }\end{array}$ \\
\hline
\end{tabular}


como en el $2^{\circ}$ milenio d.C. Mientras que de los más de 10 animales comestibles registrados, únicamente 6 (camélidos, ñandú, taruca, moluscos, roedores y quirquinchos) se mantienen con cierta continuidad durante ambos milenios. También la sal, cuyas evidencias muestran un uso continuo en ambos milenios, puede ser incluida dentro de los alimentos comestibles y por ende en los procesos culinarios para el área. Si bien, ésta no se presenta en los sitios como un componente propio del registro arqueológico, por sus características intrínsecas para su conservación, su explotación y asociación con los materiales cerámicos en el sitio La Salina hacen pensar en su uso como elemento comestible por parte de los grupos prehispánicos del área.

En síntesis, resulta que de los más de 20 tipos de alimentos (entre plantas y animales) registrados hasta el momento en los sitios arqueológicos de las tierras bajas de Tucumán, sólo la mitad de ellos muestran una cierta continuidad en su utilización a lo largo del tiempo.

\section{Discusión}

La distribución de los alimentos identificados, su relación con los tipos de sitios, sus contextos de hallazgos y variedades domesticas o silvestres, permiten abordar una serie de cuestiones relacionadas con la producción de alimentos, en sus diferentes formas, para el área de las tierras bajas de Tucumán.

Hasta hace poco tiempo, las evidencias regionales más cercanas de la utilización de plantas cultivadas para el área de estudio procedían de los contextos funerarios Candelaria de las serranías de Pampa Grande (Salta), de donde se recuperaron granos de maíz y poroto fechados en 1720 \pm 50 AP (Lema, 2009). Con los hallazgos de microfósiles y macrorestos de maíz (Zea mays), poroto (Phaseolus vulgaris) y zapallo (Cucurbita máxima) obtenidos en Yago, Zárate Nuevo-Finca Zavalía, Santa Rosa I y II y las ocupaciones tempranas de Yánimas 1, que resultan sincrónicos con los de Pampa Grande, es posible postular ahora la utilización temprana de plantas cultivadas para las tierras bajas de Tucumán.-

A diferencia de los asentamientos prehispánicos ubicados en los valles y quebradas de altura de la provincia de Tucumán, donde las sociedades aldeanas se caracterizaron durante el $1^{\circ}$ milenio d.C. por un uso común del espacio doméstico y productivo (González y Núñez Regueiro 1960; Berberián y Nielsen 1988; Cremonte 1996; Caria et al. 2006; Salazar y Franco Salvi 2009; Caria 2010; Oliszewski et al. 2017), en las tierras bajas tucumanas esta relación no es claramente visible. Como ya se señalara anteriormente, aunque existen evidencias que muestran el procesamiento y consumo de plantas domesticadas en el área de trabajo, hasta el momento no ha sido posible identificar los espacios de producción agrícola. También resta por establecer el peso de su importancia relativa en la economía de los grupos con respecto a la recolección de vegetales silvestres.

Como propone Lema (2009), es probable que durante el $1^{\circ}$ milenio d.C., y como sucede hasta la actualidad en regiones del NOA como las Yungas o la Puna, la agricultura se desarrollara en un formato productivo del tipo hortícola. Este está caracterizado espacialmente por tener lugar en un área de dimensiones reducidas, próxima a la zona de residencia y caracterizada "particularmente por una forma de producción vegetal donde no hay una actitud seleccionadora homogeneizadora, siendo un espacio donde conviven múltiples formas de relación ser humano-planta" (Lema 2009:692). Así, la posibilidad de una horticultura para los sitios donde se asentaron las poblaciones del primer milenio d.C. en el área, podría servir para explicar, en parte, la dificultad de visualizar materialidades asociadas al cultivo de plantas en el registro arqueológico. En la misma línea, creemos resulta necesario a futuro, profundizar en los estudios de procesos de formación de sitio, particularmente a través de análisis geoquímicos y pedológicos, que permitan visualizar áreas de actividad en los sitios y sus espacios próximos. Si bien la información etnohistórica para el área no hace referencia específica a los modos de producción agrícola, resulta interesante considerar la posibilidad de prácticas como la de "roza y quema" para la preparación de suelos destinados a huertos. La utilización de la misma se encuentra ampliamente extendida en los grupos que habitaron y habitan las forestas tropicales de Centroamérica y Sudamérica (Meggers 1996, 2010; Clement 2006). Los numerosos elementos culturales de raíces amazónicas presentes y reconocibles en las sociedades de las tierras bajas de Tucumán para estos momentos (Heredia 1974, González 2007, Núñez Regueiro y Tartusi 1987, 2003; Alberti 2007, 2012; Moreno 2019), permiten hipotetizar la posible utilización de esta práctica durante el pasado prehispánico como método de preparación del espacio destinado a los cultivos.

Es interesante mencionar, como señala Meggers (1996, 2000), que durante el proceso de preparación del suelo por el método de "roza y quema", que dura alrededor de un mes dependiendo de los grupos etnográficos analizados, previo a la quema, se remueven plantas y malezas no deseadas y se derriban los árboles de mayor porte, pero conservándose la parte inferior de los troncos que sirven para estructurar el huerto futuro. Posteriormente, los cultivos se siembran de manera dispersa y heterogénea, reproduciendo de alguna manera su distribución natural en un contexto silvestre. Esta práctica de dispersión, junto a la alternancia estacional de los diferentes cultivos, minimiza por un lado el accionar de insectos o plagas perjudiciales y contribuye, por otro lado, al no agotamiento temprano de los suelos. Con posterioridad al abandono del sector destinado al cultivo, luego de dos o tres años de utilización en promedio, el bosque puede, 
gracias a las prácticas conservacionistas señaladas, regenerarse completamente, resultando por lo tanto muy difícil identificar los antiguos espacios hortícolas. Esta característica de la práctica de "roza y quema", orientada a una agricultura de huertos, implica, necesariamente, en términos del registro arqueológico una baja visibilidad, la que como ya se mencionara, debe ser salvada con la utilización de métodos y técnicas dirigidos específicamente a su identificación. A pesar de esto último, es importante mencionar que tanto la reocupación periódica de espacios para cultivos, como aquellos destinados para el emplazamiento de los núcleos habitacionales, constituyen, por ejemplo, una práctica frecuente entre los pueblos de la Amazonía (Meggers y Miller 2006), por lo que la ausencia de estructuras y/o rasgos perdurables puede verse compensada con la existencia de una señal antrópica más notoria en suelos y sedimentos. Situaciones análogas podrían haber tenido lugar en el área de estudio durante las ocupaciones del $1^{\circ}$ milenio d.C. En ese sentido, los fechados obtenidos del sitio Yago muestran al menos tres momentos de ocupación $(1702 \pm 55,1466 \pm 43$ y $1359 \pm 57$ años AP) y constituyen una primera evidencia de espacios persistentes para el área en el contexto de los denominados grupos Candelaria (Caria et al. 2012; Gómez Augier 2017), tradicionalmente considerados como habitantes de asentamientos efímeros o temporarios.

Si, sobre la base de la evidencia obtenida hasta el momento de los sitios correspondientes al $1^{\circ}$ milenio d.C. en el área de trabajo, aceptamos la existencia de una agricultura de tipo hortícola, entonces es necesario discutir y analizar su relevancia y las interrelaciones económicas dentro y fuera de la misma.

Evidencias de macrorestos en alguno de los sitios arqueológicos, con cronologías afines, muestran registros de especímenes silvestres junto a especies domesticadas, y sugieren una estrategia mixta sostenida a lo largo del tiempo, más que una evolución o desarrollo hacia una economía hortícola dependiente (Gómez Augier 2017). En este sentido, el trabajo de Lema (2009) sobre materiales vegetales arqueológicos procedentes de contextos formativos en las ya mencionadas cuevas de Pampa Grande, y atribuidos a grupos portadores de los estilos cerámicos Candelaria, sugieren una coexistencia de formas malezoides/silvestres y domesticadas, dejando abierta la discusión en torno al peso específico de las prácticas de recolección y agricultura para las mismas. De acuerdo a Lema (2009:491) "en Pampa Grande hay una coexistencia de plantas con distinto grado de manipulación más que una sucesión en el tiempo de las mismas", esta observación corroboraría, en el plano productivo, la estabilidad característica en los modos de vida de los grupos del $1^{\circ}$ milenio d.C. en los sitios de las tierras bajas de Tucumán (Gómez Augier 2017).
Por otra parte, los análisis de microfósiles realizados en los artefactos de molienda de los sitios estudiados muestran el procesamiento de semillas y frutos silvestres junto a vegetales domesticados (principalmente maíz y poroto), lo que sugieren una estrategia mixta. La práctica de una agricultura de tipo hortícola como complemento en la obtención de recursos vegetales silvestres lleva aparejados, como ya se mencionara, comportamientos que poseen un bajo correlato en términos de materialidad y visibilidad en el registro arqueológico. La aparente estabilidad en los modos de vida de los grupos humanos, su iconografía cerámica y el arte rupestre presentes en alguno de los sitios del área sugieren una relación, a través de la cosmovisión, con plantas y animales basadas en una ontología de "recíprocos" sensu Descola (2012), Alberti (2002, 2010), Gómez Augier (2017) y Moreno (2019). Según Descola (2012), en la mayor parte de los pueblos de las tierras bajas de Sudamérica no existen diferencias ontológicas tajantes entre humanos por un lado y animales y vegetales por el otro. Las relaciones entre humanos y no humanos se presentan como relaciones entre comunidades en función de acciones utilitarias de subsistencia en ambos sentidos. Así, la naturaleza puede ser vista como sujeto de una relación social, como una prolongación del mundo de la casa familiar, lo que la convierte en doméstica hasta en sus reductos más inaccesibles. Siguiendo esta lógica, no existe una verdadera ruptura espacial en términos de domésticonatural; la objetivación a través de la materialidad (con sus implicancias en el registro arqueológico) no es necesariamente un requisito para la aprehensión del entorno. Por ello, Descola (2012:29) se pregunta si " ¿se puede hablar de apropiación y transformación de los recursos naturales cuando las actividades de subsistencia se declinan en la forma de una multiplicidad de apareamientos individuales con elementos humanizados de la biósfera? ¿Se puede siquiera hablar de espacio silvestre con referencia a esa selva apenas rozada por los humanos, y que estos describen, empero, como un inmenso huerto cultivado cuidado por un espíritu?". Si bien, las actividades y técnicas de subsistencia tienden a producir la sensación de un contraste entre un núcleo de actividad más o menos duradera y una periferia poco frecuentada, el hecho de reconocer discontinuidades espaciales entre sectores no implica de manera alguna, por ejemplo, que ciertos ámbitos se perciban en lo sucesivo como salvajes (Descola 2012).

Volviendo a la discusión sobre la importancia de la recolección respecto al cultivo de vegetales en los sitios del $2^{\circ}$ milenio d.C. del área de estudio, resulta interesante que los análisis polínicos para el sitio Ticucho 1, en asociación espacial con Yago, muestran de acuerdo a Caria (2004) una economía basada en el aprovechamiento de los recursos silvestres a través de la recolección, sin evidencias de procesamiento de plantas cultivadas. No obstante, las evidencias de microfósiles de maíz presentes 
en los artefactos de molienda estaría mostrando la posibilidad, al menos, de un complemento basado en el cultivo del maíz. Es cierto que cronológicamente las ocupaciones de ambos sitios se encuentran separadas por un intervalo considerable, siendo Ticucho 1 más tardío que Yago, no obstante sería lógico pensar en una secuencia progresivamente volcada a la producción de alimentos y no a la inversa, como estarían mostrando las evidencias obtenidas en estos sitios.-

Así mismo, la presencia de mistol en el sitio Ticucho 1 confirmaría la propuesta de Caria (2004) que atribuye a los ocupantes del sitio una estrategia basada más en la recolección de frutos silvestres y en la caza; la presencia de maíz en estos contextos, permite proponer ahora a la horticultura como un complemento o alternativa a esa estrategia.

Por otra parte, como ya se mencionara, los oxalatos de calcio romboidales afines a cebil (Anandenanthera colubrina) confirmarían la persistencia de la práctica del consumo de este enteógeno para momentos relativamente tardíos. No se encontraron en Ticucho 1 artefactos tradicionalmente relacionados al consumo de esta sustancia como pipas, tabletas o tubos para inhalar. En el sitio Bahía, por ejemplo, se recuperaron numerosos fragmentos de pipas asociados a cerámica Condorhuasi tricolor y Candelaria. También en el sitio Yago se recuperó un fragmento de hueso de ave formatizado en forma de tubo, que por sus características se asemejan a las usadas en otros sitios del NOA para inhalar (Caria et al. 2011). La cercanía espacial entre los sitios refuerza la idea de que el mismo estuviera vinculado a la utilización de este psicoactivo, con lo que su consumo podría considerarse una práctica frecuente, mantenida en el área durante un lapso de tiempo considerable. Otro aspecto interesante, respecto a la presencia de cebil en Ticucho 1, gira en torno al contexto asociado a su consumo; en este caso no se identificaron espacios fuera de lo doméstico que permitan suponer la existencia de un lugar diferenciado ligado a lo ritual, como sí sucede en el sitio Yánimas 1, donde claramente se vislumbran dichos espacios.

Otro punto a tener en cuenta, en relación a las evidencias presentadas, es el rol de los alimentos identificados en los procesos de intercambio y circulación de bienes dentro y fuera del área de estudio. Así, es muy probable que las poblaciones de las tierras bajas practicaran alguna de las diferentes formas de complementariedad identificadas para varios sectores del NOA (Scattolin 2007; Yacobaccio 2012), adaptándolas en función de las necesidades de las poblaciones a lo largo del tiempo, como por ejemplo el caso de la sal obtenida en el sitio Las Salinas. Por otra parte, el fortalecimiento de redes de intercambio, solidaridad y complementariedad podrían haberse fortalecido en el contexto de un ambiente cambiante, como estrategia de mitigación de efectos adversos en el ambiente como las identificadas para diferentes momentos de los últimos dos mil años en el área (Caria 2004; Gómez Augier y Caria 2015). Otro elemento que torna visible estas redes de circulación es la cerámica. El estilo Candelaria constituye la cerámica predominante en los sitios del área, aunque es frecuente encontrar además estilos considerados foráneos en contextos domésticos como ser los estilos Vaquerías, Condorhuasi, Aguada y Sunchituyoj (Caria et al. 2011; Caria y Gómez Augier 2015; Miguez y Caria 2015; Gómez Augier 2017). Si bien no están claros aún los términos de estas relaciones (Caria 2004, 2007), su presencia pone de manifiesto la existencia de interacciones entre poblaciones, posiblemente a través redes de intercambio y/o tráfico caravanero sin poder estimar el rango temporal de su operatividad. Por ejemplo, los camélidos presentes en la mayoría de los sitios podrían haber estado funcionando, además de alimento, para el transporte de cargas. Otro producto es, si bien no alimenticio pero con un rol importante en los procesos sociales prehispánicos, el cebil (Anadenthera colubrina). Este lo encontramos dentro y fuera del área de trabajo (sitios Ticucho 1, Yánimas 1 y Bajo Los Cardones) (Miguez y Caria 2015; Chiappe Sánchez, 2007) y refuerzan la idea de vínculos estrechos entre las poblaciones ubicadas en las tierras bajas con los valles y quebradas de altura, posiblemente a través del tráfico caravanero (Caria et al. 2009; Caria y Gómez Augier 2015; Gómez Augier 2017).

En sintonía con la línea argumental anterior es importante discutir la relevancia del pastoralismo y cría de camélidos en relación al movimiento y circulación de bienes. Los hallazgos de restos de camélidos (adultos, juveniles y neonatos) en las excavaciones de los sitios de Bahía, Yago, Tambo, Mortero Hachado, El Timbó y Yánimas 1, confirman la utilización plena y sostenida en el tiempo de este recurso en las tierras bajas y podría sugerir una actividad ganadera in situ (Caria et al. 2011). La presencia del recurso camelidae debe entenderse, creemos entonces, no como un elemento secundario o complementario de la economía, es decir como transporte únicamente, sino como uno equivalente a los de la caza, recolección y horticultura en términos de importancia para la alimentación. La ausencia de corrales de piedra típicos, ha dificultado la visualización e identificación de los espacios de cría, aunque se han registrado estructuras de piedra que podrían haber tenido la función de corrales como en el caso del sitio Moya (Caria 2004). Es posible pensar, como ya se señalara, que los camélidos desempeñaron un papel central en las redes de intercambio mediante el tráfico caravanero de sal, obsidianas y cerámicas, por lo que su presencia en las tierras bajas podría haber tenido una doble función como alimento y transporte. En ese sentido, podría postularse que algunos de estos grupos caravaneros pudieron tener su origen no en la región de la Puna o los valles occidentales, sino en las tierras bajas desde donde 
enlazarían poblaciones localizadas en otros ambientes: ambas posibilidades, creemos, no resultan mutuamente excluyentes. La representación frecuente de camélidos en la alfarería de estilo Candelaria, con claros signos de acondicionamiento para la carga y el transporte, permiten considerar la posibilidad de esta alternativa.

\section{Conclusiones}

Los resultados obtenidos de nuestro análisis y su discusión nos permiten proponer una serie de cuestiones sobre la alimentación prehispánica en las tierras bajas de Tucumán. La primera de ellas es la importancia y el rol de las distintas especies de plantas y animales que aparecen en el registro arqueológico de los sitios analizados. El maíz, el zapallo y el poroto son los tres productos cuya presencia se encuentran presentes en vario de los sitios, ya sea como microfósiles en instrumentos de molienda o macrorestos en contextos domésticos o funerarios/ceremoniales. En tanto las formas silvestres de algarrobo, molle, chañar y mistol aparecen como microfósiles, producto de su procesamiento en instrumentos de molienda y como macrorestos asociados a contextos domésticos. El tala, el molle y la jarilla, en forma de registro polínico y de macrorestos, indicarían su probable uso como recursos madereros para la combustión de los alimentos registrados. En el caso del cebil, si bien no se lo considera un alimento sino un enteógeno, cobra importancia por su registro en instrumentos de molienda que fueron utilizados para el procesamiento de otros alimentos y en un espacio plenamente doméstico, como es el caso del sitio Ticucho 1. Esto último lleva a plantearnos dos explicaciones alternativas: a) que estos artefactos de molienda hayan sido empleados para moler distintas cosas (alimentos y enteógenos), sin que exista por lo tanto una vinculación directa entre lo que se procesaba y las acciones para las que estaban destinadas y b) que esta sustancia psicoactiva jugó un rol complementario en los procesos de ingesta de los alimentos registrados, es decir en una acción de índole ritual, donde los alimentos adquirían un sentido simbólico. Cualquiera de estas dos alternativas deberá ser contrastada a futuro con nuevos datos contextuales.

En cuanto al rol de los alimentos de origen faunísticos registrados para el área, podemos inferir una ingesta variada de animales propios de los diferentes ambientes que caracterizan a las tierras bajas. Su presencia en mucho de los sitios analizados, principalmente en contextos domésticos, indicarían su consumo como alimento. Si bien es necesario aclarar que, dada la variación en la calidad de la información existente para cada sitios sobre los contextos de hallazgo y la falta de estudios tafonómicos de los registros de fauna, animales como los roedores, el gato montés y los reptiles, ameritan ser considerados como "probablemente consumidos" hasta tanto no se tengan datos concretos sobre la forma en que sus restos ingresaron al registro arqueológico. Así mismo, es importante destacar que los camélidos son el único alimento animal que se encuentra registrado desde el $1^{\circ}$ hasta el $2^{\circ}$ milenio d.C. en nuestra área. Particularmente, y por los motivos expuestos anteriormente, resulta prematuro realizar una distinción entre camélidos silvestres y domesticados, pero lo cierto es que su registro en casi la totalidad de los sitios analizados y las marcas de cortes y combustión en mucho de sus restos, revelan claramente su consumo como alimento.

Respecto a los procesos de preparación de los alimentos registrados, sólo podemos decir, por el momento, que han sido procesados en instrumentos de molienda en el caso de las plantas, tanto silvestres como cultivadas. En un solo caso se ha encontrado evidencia de tostado del maíz en el proceso de molienda, mientras que por acción directa al fuego se registraron maíz y poroto. De igual manera, no podemos descartar el uso de vasijas para la realización de comidas hervidas que contengan estos vegetales. Un análisis de las superficies internas de vasijas utilitarias podrán brindarnos, a futuro, evidencias de esto último. Con respecto a las formas de preparado de los animales, por el momento, el análisis tafonómico del registro indica acción directa sobre el fuego. En los procesos de elaboración de todos estos alimentos, cabe preguntarse qué rol tuvo la sal en los mismos. La presencia y evidente uso de extracción de ésta en el sitio Las Salinas, de clara ocupación multi-temporal e interrelaciones espaciales establecidas a través de los estilos cerámicos presentes, debió resultar fundamental, no sólo en los modos de circulación de la misma, dentro y fuera del área, sino también en las actividades culinarias desarrolladas por los grupos prehispánicos del área por su rol en la conservación, palatabilidad, procesos metabólicos humanos y animales, entre otros.

La información generada hasta el momento nos permite concluir que los grupos prehispánicos de las tierras bajas que ocuparon el actual territorio tucumano utilizaron una gran variedad de alimentos comestibles en forma natural o preparada. La práctica de la molienda de granos como el maíz, semilla de zapallo, poroto, algarrobo, chañar y mistol, evidencian el uso de estos recursos en el preparado de harinas para su consumo, así como su uso directo como alimento, según los restos carbonizados presentes en algunos sitios. Este complejo de granos cultivados y silvestres utilizados en la preparación de comidas implica que los grupos del área debieron practicar mecanismos de control de los mismos, ya sea a través de la horticultura junto a la caza y cría de animales, mayoritariamente locales, en complementación con los recursos obtenidos mediante redes de intercambio, reciprocidad y/o explotación directa de diferentes pisos ecológicos.

Las preguntas y líneas de investigación a encarar en el futuro próximo sobre la alimentación prehispánica de las tierras bajas en Tucumán permitirán generar un esquema más detallado de los procesos sociales, económicos e 
ideacionales de sus grupos prehispánicos e integrarlos así con los del resto del Noroeste argentino.

San Miguel de Tucumán, 27 de abril 2020

\section{Agradecimientos}

Este trabajo se enmarca en el PIUNT 26G/610 dirigido por el Dr. Mario Caria.

\section{Bibliografía}

Alberti, B. (2007). Destabilizing meaning in anthropomorphic forms from Northwest Argentina. Journal of Iberian Archaeology 9(10):209-229.

Alberti, B. (2012). Cut, pinch and pierce: image as practice among the Early Formative La Candelaria, first millennium AD, Northwest Argentina. Encountering Imagery Materialities, Perceptions, Relations. Stockholm Studies in Archaeology (57):13-28.

Arenas, P. (2003). Etnografía y Alimentación entre los TobaNachilamole\#ek y Wichí-Lhuku'tas del Chaco Central (Argentina). UBA. Buenos Aires.

Ávido, D. (2012). Conceptos y métodos para el estudio zooarqueológico de la cocción de los alimentos. M. P. Babot, M. Marchoff, M. Pazzarelli (eds.), Las manos en la masa. Arqueologías, Antropologías e Historias de la Alimentación en Suramérica, pp. 553-575. Sociedad Argentina de Antropología.

Bárquez, R., M. Mares, y R. Ojeda. (1991). Mamíferos de Tucumán. Oklahoma Museum of Natural History, University of Oklahoma.

Berberián, E. y D. Soria. (1970). Investigaciones arqueológicas en el yacimiento de Zárate (Dpto. Trancas, Tucumán). Revista Humanitas XVI, 22: 165176.

Berberián, E., J. García Azcárate, y M. Caillou. (1977). Investigaciones arqueológicas en la región del Dique El Cadillal (Tucumán-Argentina). Los primeros fechados radiocarbónicos. Relaciones de la Sociedad Argentina de Antropología XI: 31-52.

Berberián, E. y A. Nielsen. (1988). Sistemas de asentamientos prehispánicos en la etapa formativa del valle de Tafí. Berberián, E. (ed.), Sistemas de asentamientos prehispánicos en el valle de Tafí, pp. 21-51. Córdoba

Brown, A y S. Pacheco. (2005). Propuesta de actualización del mapa eco regional de la Argentina. Brown, A., U. Martínez Ortíz y J. Acerbi (eds.), La situación ambiental Argentina, pp.134-156. Buenos Aires.
Cabrera, A. (1976). Regiones fitogeográficas de Argentina. ACME. Buenos Aires.

Cadena, B. y C. Moreano. (2012). La alimentación en tiempos pretéritos, una reflexión acerca de la trascendencia de la comida en la cultura y en el entorno biológico de las poblaciones humanas. M. P. Babot, M. Marchoff, M. Pazzarelli (eds.), Las manos en la masa. Arqueologías, Antropologías e Historias de la Alimentación en Suramérica, pp. 339-360. Sociedad Argentina de Antropología.

Califano, M. (1976). El chamanismo mataco. Scripta Ethnológica 3(2):7-60.

Capriles Flores, J. (2002). Intercambio y uso ritual de fauna por Tiwanaku: Análisis de pelos y fibras de los conjuntos arqueológicos de Amaguaya, Bolivia. Estudios Atacameños 23:33-51.

Caria, M. (2004). "Arqueología del paisaje en la cuenca Tapia-Trancas y áreas vecinas (Tucumán, Argentina)". Facultad de Ciencias Naturales e IML, Universidad Nacional de Tucumán, Argentina. Tesis Doctoral inédita.

Caria, M. (2007). Manejo del espacio geomorfológico en un valle intermontano de la provincia de Tucumán durante la época prehispánica. Acta Geológica Lilloana 20 (1): 29-40.

Caria, M. y S. Garralla. (2006). Evolución paleoambiental del sitio Acequia (Trancas-Tucumán-Argentina) a partir de indicadores polínicos. Actas de Trabajos III Congreso Argentino de Cuaternario y Geomorfología, Tomo I: 75-84. Universidad Nacional de Córdoba.

Caria, M.; N. Oliszewski y J. Martínez. (2006). Geomorfología y Arqueología de la quebrada del río de Los Corrales (El Infiernillo, Tafí del Valle. Tucumán, Argentina). III Congreso Argentino de Cuaternario y Geomorfología. Actas 1: 145-154. Córdoba.

Caria, M y J. Sayago. (2008). Arqueología y ambiente en un valle intermontano del piedemonte oriental de las Cumbres Calchaquíes (Tucumán, Argentina). Runa 29: 7-22.

Caria, M., P. Escola, J. Gómez Augier y M. Glascock. (2009). Obsidian circulation: new distribution zones for the Argentinean northwest. Bulletin International Association for Obsidian Studies: 5-11.

Caria, M. (2010). Agricultura arqueológica de los sitios "El Divisadero" y "Yasyamayo" (Cumbres CalchaquíesTucumán-Argentina). Bárcena y Chiavazza (eds.), Arqueología Argentina en el Bicentenario de Mayo, Tomo V, Capítulo 36: 2021-2026. Mendoza. 
Caria, M., J. Gómez Augier, H. Cruz y J. Zapatiel. (2011). Aportes a la construcción de la variabilidad material de un sitio arqueológico en el piedemonte Oriental de Cumbres Calchaquíes. Tucumán. Revista Comechingonia $\mathrm{N}^{\circ} 14: 133-154$.

Caria, M. y J. Gómez Augier. (2015). Arqueología en espacios contrastados en los piedemontes oriental y occidental de Cumbres Calchaquíes (TucumánArgentina) durante el $1^{\circ}$ y $2^{\circ}$ milenio de la era. Korstanje, A. y M. Lazzari (eds.), Crónicas materiales precolombinas. Arqueología de los primeros poblados del Noroeste Argentino, pp. 355-383. Sociedad Argentina de Antropología.

Caria, M. y J. Gómez Augier. (2019). Geoarqueología del sector septentrional de las tierras bajas de la provincia de Tucumán (Argentina): patrones en el uso del espacio durante la época prehispánica. Boletín Sociedad Geológica Mexicana, Vol. 71 N² 2:275-293.

Chevez, J. C. (1994). Los que se van. Especies argentina en peligro. Editorial Albatros, Argentina.

Chiappe Sánchez, N. (2007). "Sobre la construcción social de la muerte. Las prácticas funerarias en un sitio agroalfarero temprano: Bajo Los Cardones. Amaicha del Valle. Tucumán". Facultad de Ciencias Naturales e IML, Universidad Nacional de Tucumán, Tucumán. Tesis de Grado inédito.

Clement, Ch. (2006). Domesticacao de paisagens e plantas amazónicas a interacao de etnobotánica, genética molecular e arqueología. Morcote Ríos, G; Mora Camargo, S. y Calvo, C.F (eds), Pueblos y Paisajes Antiguos de la selva Amazónica, pp. 97-112. Universidad Nacional de Colombia. Bogotá.

Cremonte, M. (1996). “Investigaciones arqueológicas en la Quebrada de la Ciénaga (Dpto. Tafí, Tucumán). Facultad de Ciencias Naturales y Museo, Universidad Nacional de la Plata. Tesis Doctoral inédita.

DaMatta, R. (1987). La cultura de la mesa en Brasil. Correo de la UNESCO.

Descola, P. (2012). Más allá de naturaleza y cultura. Amorrortu Ed. Buenos Aires.

Díaz, D. (2009). Patrón alimentario, cocina y dieta: definiciones antropológicas. (Ms).

Esparrica, H. (1999). Investigaciones arqueológicas en el sitio S-TUC-TRA-21. Mortero Hachado. Dpto. Trancas-Tucumán. Actas del XII Congreso Nacional de Arqueología Argentina, Tomo I: 82-91. Universidad Nacional de La Plata. Bs. As.
García Azcárate, J. y A. Korstanje. (1995). La ocupación prehispánica de las selvas de montaña tucumanas. Brown. A. y H. Grau (eds.), Investigación, Conservación y Desarrollo en Selvas Subtropicales de Montaña, pp. 175-182, LIEY.

Gómez Augier, J y M. Caria. (2012). Los paleoambientes y los procesos culturales en el Noroeste Argentino: una aproximación desde la arqueología de Tucumán. Acta geológica Lilloana V. 24, N 1-2: 80-97.

Gómez Augier, J. (2017). “Procesos de ocupación del espacio en Cumbres Calchaquíes: un análisis desde la Geoarqueología y el paleoambiente". Universidad del Centro, Olavarría. Tesis Doctoral inédita.

Gómez Augier, J., G. Miguez y M. Caria. (2007). La Exploraçao de Sal no Setor das Terras Baixas do Noroeste Argentino durante o Formativo: ¿Espaço de Convergencia Cultural? Revista CANINDE $\mathrm{N}^{\circ} 10$ : 191-205.

González, A. R. y Núñez Regueiro V. (1960). Preliminary report on archaeological research in Tafí del Valle, $\mathrm{N}$. W. Argentina. XXXIV Internationalesn Amerikanisten Kongresses. Acta 1:485-496.

González, A. R. (2007). Arte, estructura y arqueología. La Marca editora. Buenos Aires.

Halloy, S. (1985). Climatología y edafología de alta montaña en relación con la composición y adaptación de las comunidades bióticas (con especial referencia a las Cumbres Calchaquíes, Tucumán). Michigan University Microfilms International Publ.

Heredia, O. (1974). Investigaciones arqueológicas en el Sector Meridional de las Selvas Occidentales. Revista del Instituto de Antropología 5: 73-132.

Lema, V. (2009). “Domesticación vegetal y grados de dependencia ser humano-planta en el desarrollo cultural prehispánico del Noroeste Argentino". Universidad Nacional de La Plata. Tesis Doctoral inédita.

Marschoff, M. (2007). ¿Comer o nutrirse? La alimentación como práctica social. Arqueología 13: 155-184.

Meggers, B. (1996). Amazonia. Man and Culture in a Counterfait Paradise. Smithsonian Institution. Washington DC.

Meggers, B. (2000). El Contexto Ecológico del Formativo. Formativo Sudamericano. Ediciones AbyaYala. Quito. 
Meggers, B. y Miller. (2006). Evidencia Arqueológica para el Comportamiento Social y Habitacional en la Amazonía Prehistórica. Morcote Ríos, G; Mora Camargo, S. y Calvo, C.F (eds.), Pueblos y Paisajes Antiguos de la selva Amazónica, pp. 325-348. Universidad Nacional de Colombia. Bogotá.

Meggers, B. (2010). Prehistoric America: An Ecological Perspective. Transaction Publishers. New Brunswick, New Jersey.

Miguez, G. (2010). Paisajes y espacialidades del sitio Yánimas 1 (provincia de Tucumán). Libro de Resúmenes del XVII Congreso Nacional de Arqueología Argentina, pp. 449-454. Mendoza, Argentina.

Miguez, G. y M. Caria. (2015). Paisajes y prácticas sociales en las selvas meridionales de la provincia de Tucumán ( $1^{\circ}$ milenio d.C.). Korstanje, A. y M. Lazzari (eds.), Crónicas materiales precolombinas. Arqueología de los primeros poblados del Noroeste Argentino, pp. 111-150. Sociedad Argentina de Antropología.

Miguez, G., P. Cuenya y M. Caria. (2012). Observaciones arqueopedológicas vinculadas a una ocupación prehispánica del sitio Yánimas 1 (Tucumán). Actas $V$ Congreso Argentino de Geomorfología y Cuaternario, pp. 61-70. La Plata, Argentina.

Miguez, G., G. Arréguez y N. Oliszewski. (2012). Primeros hallazgos de la forma doméstica del poroto común en el piedemonte tucumano ( $1^{\circ}$ milenio $d$. C.). Comechingonia 16: 307-314.

Moreno, E. (2019). “Aproximación a la ontología Candelaria: la iconografía del murciélago como caso de estudio". Facultad de Ciencias Naturales e IML, Universidad Nacional de Tucumán. Tesis de Grado inédita.

Murra, J. (1975). El control vertical de un máximo de pisos ecológicos en la economía de las sociedades andinas. Formaciones económicas y politicas del mundo andino, pp. 59-115, Instituto de Estudios Peruanos, Lima.

Nasif, N., M. Corbalán, A. Moreno y M. Gavícola. (2007). La explotación de recursos faunísticos en el sitio Mortero Hachado (Departamento Trancas, Tucumán). PACARINA Número Especial III: 179-185.

Nasif, N y G. Miguez. (2014). La fauna relacionada a una comunidad prehispánica del piedemonte meridional de la provincia de Tucumán (Argentina). Revista Folia Histórica del Nordeste 22: 203-232.

Núñez Regueiro, V. y Tartusi, M. (1987). Aproximación al estudio del área pedemontana de Sudamérica. Cuadernos del Instituto Nacional de Antropología 12: $125-160$.

Núñez Regueiro, V. y Tartusi, M. (2003). Procesos de interacción entre poblaciones de los Valles Intermontanos del Noroeste Argentino y las del piedemonte. Cornell, P. y Stenborg, P. (eds.), Local, Regional, Global: prehistoria, protohistoria e historia en los Valles Calchaquíes. Instituto Iberoamericano. Universidad de Göteborg.

Oliszewski, N.; Caria, M.; Martínez, J. (2017). Bienes alóctonos y sus implicancias en la Quebrada de los Corrales (El Infiernillo, Tucumán) durante el primer milenio d.C. Ortiz (ed.) Arqueología de la vertiente oriental Surandina. Interacción macro-regional, materialidades, economía y ritualidad, pp. 329-342. unas.

Olrog, C. (1995). Las Aves Argentinas. El Ateneo. Buenos Aires.

Pantorrilla, M. y V. Núñez Regueiro. (2006). Investigaciones arqueológicas en la zona de Escaba, Provincia de Tucumán: asentamientos Condorhuasi y Aguada en las Yungas. Intersecciones en Antropología 7: 235-245.

Pérez Miranda, C. (2003). Tucumán y los recursos naturales. Bifronte. Buenos Aires.

Piperno, D. y D. Pearsall. (1998). The evoluction of foraging and food production. D. Piperno y D. Pearsall (eds.), The origen of agriculture in the lowland neotropics, pp. 167-242, Academic Press.

Salazar, J. y V. Franco Salvi. (2009). Una mirada a los entornos construidos en el Valle de Tafí, Tucumán (1 - 1000 AD). Comechingonia 12: 91-108.

Scattolin, M. (2007). Santa María antes del año mil. Fechas y materiales para una historia cultural. V. Williams, B. Ventura, A. Callegari y H. Yacobaccio (eds.), Sociedades Precolombinas Surandinas: Temporalidad, Interacción y Dinámica Cultural del NOA en el ámbito de los Andes Centro-Sur, pp. 203-119. Artes Gráficas Buschi. Buenos Aires.

Yacobaccio, H. (2012). Intercambio y caravanas de llamas en el Sur Andino (3000-1000 AP). Comechingonia 16: 31-51.

Verboorst, F. (1969). Comunidades vegetales del norte Argentino. Hawkes, J. y Hjerting, J. (eds.), The Potatoes in Argentina, Brazil, Paraguay and Uruguay. Annals of Botany Memoir $N^{\circ} 3$. 
White, C., D. Pendergast, F. Longstaffe y K. Law. (2001). Social Complexity and Food System at Altun Ha,
Belize: The isotopic Evidence. Latin American Antiquity 12(4):371-393. 